\title{
Starting with the a-ha: An integrated introduction to solid and fluid mechan- ics
}

\section{Dr. Jenn Stroud Rossmann, Lafayette College}

Jenn Stroud Rossmann is Associate Professor and Department Head of Mechanical Engineering at Lafayette College. She earned her BS in mechanical engineering and the $\mathrm{PhD}$ in applied physics from the University of California, Berkeley. Prior to joining Lafayette, she was a faculty member at Harvey Mudd College. Her scholarly interests include the fluid dynamics of blood in vessels affected by atherosclerosis and aneurysm, the cultural history of engineering, and the aerodynamics of sports projectiles.

\section{Dr. Clive L. Dym, Harvey Mudd College}

Clive L. Dym is Professor Emeritus of Engineering at Harvey Mudd College. His primary interests are in engineering design and applied and structural mechanics. Dr. Dym received the PhD from Stanford University and has held appointments at a variety of schools, institute and companies over a 46 year. He has authored or coauthored 19 books and 96 refereed journal articles, and has served on the editorial boards of several journals. He is a Fellow of the ASEE, ASCE and ASME. Dr. Dym's awards include the Fred Merryfield Design Award (ASEE, 2002), the Joel and Ruth Spira Outstanding Design Educator Award (ASME, 2004), the Archie Higdon Distinguished Educator Award (Mechanics Division, ASEE, 2006), and being a co-winner of the Bernard M. Gordon Prize for Innovation in Engineering and Technology Education (NAE, 2012).

\section{Dr. Lori Bassman, Harvey Mudd College}




\title{
Starting with the a-ha: An integrated introduction to solid and fluid mechanics
}

\begin{abstract}
We have developed an introduction to continuum mechanics for sophomore students without any prior knowledge of mechanics. The essence of continuum mechanics, the internal response of materials to external loading, is often obscured by the complex mathematics of its formulation. By building gradually from one- to higher-dimensional formulations, and integrating multiple case studies, we are able to make this subject more accessible to undergraduates. Students develop both physical intuition for, and the mathematical techniques to describe, solid and fluid behavior. At the same time they gain a unique appreciation for the connections between solid and fluid mechanics. These connections are often only revealed to advanced undergraduates and graduate students who elect to study continuum mechanics, when a curtain is pulled back to reveal the $a$-ha - the similarities between solids' and fluids' governing equations, and the connections between their constitutive laws. In our approach, we start with this $a-h a$.
\end{abstract}

Through this approach, students appreciate the behavior of engineering materials as a spectrum with Hookean solids at one extreme, and Newtonian fluids at another, with many complex behaviors (for example, that of biomaterials) in between. Our approach demonstrates the connections between solid and fluid mechanics, as well as the larger mathematical issues shared by both fields, to students who have not yet taken courses in fluid mechanics and/or strength of materials. The context and foundation provided by this educational strategy effectively prepare students to continue to study either solid or fluid mechanics, apply computational methods, or specialize in the connections themselves by returning to a deeper study of the overarching field of continuum mechanics.

The continuum approach permits students to synthesize and analyze knowledge, and our use of case studies integrates cultural, political, and ethical issues into a sociotechnical understanding of engineering mechanics. We describe the development and implementation of this approach at one institution, and how we resolved the challenges involved in transferring the approach to a second institution. We discuss several refinements to our methodology that resulted from broadening our audience. Assessment results from over 10 years, at two institutions, are evaluated and interpreted.

\section{Introduction}

In traditional engineering curricula, the subjects of solid and fluid mechanics are taught separately, in distinct courses that focus primarily on ideal species of both solids and fluids: linearly elastic, Hookean solids and Newtonian fluids, respectively. Those students who elect to study continuum mechanics, either as advanced undergraduates or graduate students, are availed of a perspective from which the two fields' connections may be seen. 
Although this privileged perspective provides a beautiful, panoramic view, the essence of continuum mechanics can be obscured by the complex mathematics of its formulation: highorder tensors and partial differential equations. This paper describes an approach that begins with this wide-angle view, and builds gradually from one- to higher-dimension analyses. In essence, we start with the $a$-ha of continuum mechanics: the similarities between solids' and fluids' governing equations, and the connections between their constitutive laws. Stress and strain are always understood to be tensors, and students are reminded that one-dimensional analyses are simplifications of more complex conditions: they have "zoomed in" on regions within the larger landscape of the mechanics of materials.

A key aspect of our implementation is the integration of multiple case studies, involving the application of course material in relevant real-world situations from the design of biomedical devices to the construction of the Three Gorges Dam. In addition to demonstrating the utility of the modeling and analysis methods taught, these case studies address ethical and societal issues. Like the continuum $a-h a$, these issues are introduced as a natural part of engineering mechanics from the very beginning, and our students' ability to appreciate and negotiate these issues continues to develop throughout their subsequent coursework.

Such an approach has clear benefits for students, who: (a) reinforce their understanding of the fundamentals of both solid and fluid mechanics; (b) appreciate the mathematics necessary to model, design, and analyze complex systems; (c) see how the details cohere into the panoramic big picture of continuum mechanics; and also (d) integrate achievement of outcomes related to societal context and ethical practice into their technical understanding of mechanics. This integrative introductory course may be valuable to faculty seeking to conserve technical understanding in the face of pressures to streamline curricular requirements, to faculty hoping to inculcate interdisciplinary methods and values, for example those in bioengineering; and to those who view engineering as a sociotechnical enterprise. We have found it possible to foster understanding at a high Bloom's level - synthesis, analysis, and evaluation - and to integrate social and technical analyses without appreciable loss in technical content.

While this approach and course were developed in a specific institutional context, we will describe in the subsequent sections how the approach has evolved and been transferred to other institutions, and the process and results of assessment.

\section{Course Development: Context and Evolution}

We first developed our course at an undergraduate college focusing on math, science, and engineering. The general engineering program $^{1}$ is unified by the concepts that design is the central activity of engineering; that engineers typically design systems; and that such design requires good models and rigorous analyses of the physical systems. Students complete both cornerstone $^{2}$ and capstone ${ }^{3}$ design projects that are inherently interdisciplinary, and fulfill curricular requirements that provide a broad education in engineering fundamentals.

Because the program leads to an ABET-accredited, unspecialized degree in Engineering, faculty must ask themselves what an exceptionally competent engineer ought to know about a wide 
range of topics in order to be able to practice or pursue graduate work in a specific engineering discipline. In such a general program, students take only one required introductory course that addresses "mechanics" topics (as well as one course each in the fundamentals of materials science; electrical engineering; experimental engineering; chemical engineering thermodynamics; and computer engineering). These are scaffolded by a sequence of courses in systems and controls theory, and four semesters of design projects permit application of theoretical concepts from across the curriculum. For many years, this one mechanics course consisted of two half-courses in dynamics and in strength of materials, which involved significant repetition of introductory physics. Following a comprehensive internal review of our curriculum in 1999-2000, our many revisions included an overhaul of our introductory mechanics course. We felt we would provide our graduates with necessary knowledge by including fluid mechanics in the course, and by using the continuum mechanics approach to link the topics in solid and fluid mechanics, making the course feel more organic as a single semester than the previous incarnation ${ }^{4}$.

Our implementation of the course has evolved over time. The earliest offering of the course emphasized mathematical sophistication and an immediate reveal of the full, three-dimensional $a$-ha; subsequent offerings developed the gradual building from single to multi-dimensional situations, and clarified the central idea of the course as a focus on:

\section{[all kinds of] materials' responses to [all kinds and combinations of] external loading.}

The socio-technical case studies highlighting applications of the course topics began as small illustrations, then grew in scope and scale, as well as in number. As the course evolved, hands-on demonstrations and experiments were integrated; these also became larger-scale and more numerous as we continued to refine our approach.

\section{Course Content and Pedagogical Approach}

We take a consistent continuum approach to considering the responses of solids and fluids to external loading, by repeatedly emphasizing the idea that complete continuum models account for: the kinematics of deformation; the intensity of internal forces, or stress; constitutive laws that relate stress to deformation; and Newton's second law. First, we develop these four fundamental concepts in one dimension, and apply them to the axially-loaded bar. (At this point, indeterminate structures are introduced.) Next, we establish the four fundamental concepts in two and three dimensions, and then introduce the stress and strain tensors in Cartesian coordinates. Our next step is to apply the concepts to torsional loading and to pressure vessels; the equations of stress transformation and Mohr's circle enable us to develop more complete descriptions of stress states. We then discuss beam theory and column buckling, again delineating the four elements of continuum mechanics modeling. In the last third of the course, our modeling extends to fluids, once again considering the kinematics of deformation, stress, constitutive laws that related stress to deformation rate, and Newton's second law. Always of interest and under discussion are the similarities and differences between solids and fluids, and the assumptions under which our theories are valid. 
To help students appreciate the "panoramic perspective" of the course, we highlight the connections between solid and fluid mechanics by developing a spectrum of material behavior, as shown in Figure 1. This spectrum has the limiting behavior of Hookean solids and Newtonian fluids at its extremes, and all the complexities of "real" engineering materials, including nonlinearity and viscoelasticity, in between. Students can thus recognize the extremes of the spectrum as representing idealizations (rather than the "norm," as they might expect after two traditional courses in "strength of materials" and "fluid mechanics"), and can see that the spectrum itself is continuous, explicitly connecting the various behaviors addressed in the course. This perspective is particularly valuable for students interested in biological applications, as the complex behaviors of biomaterials are thus a natural part of the spectrum of engineering material behavior, rather than exceptions to the rules made for more traditional materials.

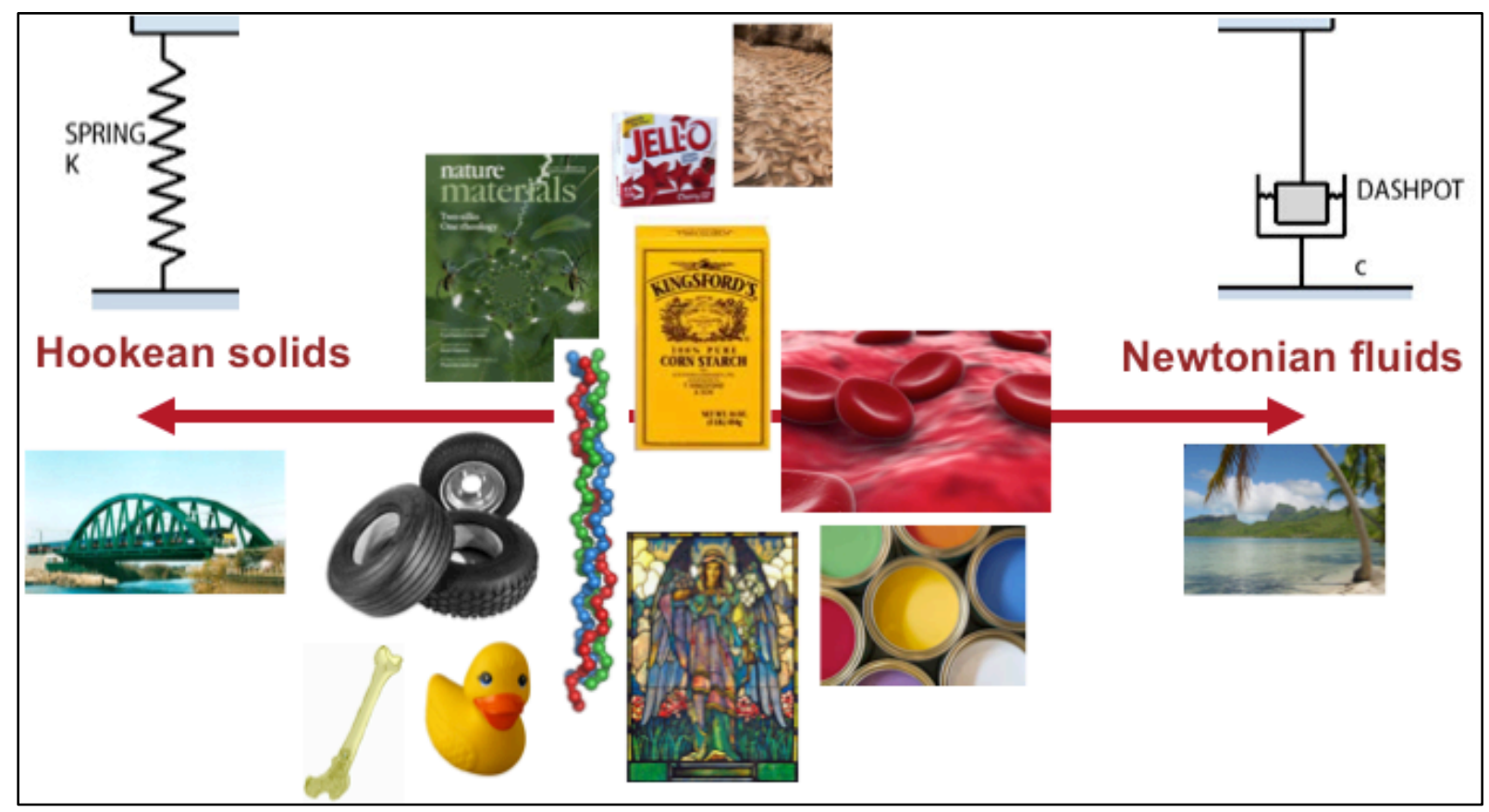

Figure 1. Spectrum of Behavior of Engineering Materials

The topical outline for the course is shown in Table 1. As most published introductions to continuum mechanics are intended for more advanced readers (e.g. Refs 5-7), the authors prepared detailed course notes to guide students through the material. After several generations of refinements, these notes were published in book form in 2008, and a second edition has just been published ${ }^{8}$. The table of contents of this text strongly resembles the outline in Table 1. 
Table 1. Topical outline for integrated introduction to solid and fluid mechanics

\begin{tabular}{|c|c|}
\hline \multirow[t]{2}{*}{ Introduction } & Definition of continuum \\
\hline & Newton's laws, vectors \\
\hline \multirow{6}{*}{$\begin{array}{l}\text { Strain and Stress in One } \\
\text { Dimension }\end{array}$} & Kinematics of deformation: strain \\
\hline & Method of sections and stress \\
\hline & Constitutive Laws \& equilibrium \\
\hline & Axially loaded bars \\
\hline & Thermal effects \\
\hline & Properties of engineering materials \\
\hline Case Study & Hyatt Regency Walkways \\
\hline \multirow{4}{*}{$\begin{array}{l}\text { Strain and Stress in Higher } \\
\text { Dimensions }\end{array}$} & Poisson's ratio \\
\hline & Strain and stress tensors \\
\hline & Generalized Hooke's law \\
\hline & 2D elasticity \\
\hline \multirow{4}{*}{$\begin{array}{l}\text { Applying Strain and Stress in } \\
\text { Higher Dimensions }\end{array}$} & Torsion \\
\hline & Pressure vessels \\
\hline & Transformation of stress and strain \\
\hline & Failure prediction criteria \\
\hline Case Study & Pressure Vessels \\
\hline \multirow[t]{3}{*}{ Beams } & Method of sections \\
\hline & Shear and moment diagrams \\
\hline & Normal and shear stresses in beams \\
\hline Case Study & Physiological Levers \& Repairs \\
\hline \multirow[t]{2}{*}{ Beam Deflections } & Integration methods \\
\hline & Strain energy \\
\hline Case Study & Truss-based Airplane Wings \\
\hline Column Buckling & Euler theory and eccentricity \\
\hline Case Studies & $\begin{array}{l}\text { World Trade Center; } \\
\text { Hartford Civic Arena }\end{array}$ \\
\hline \multirow{2}{*}{$\begin{array}{l}\text { Connecting Solid and Fluid } \\
\text { Mechanics }\end{array}$} & Pressure, viscosity, surface tension \\
\hline & Motion \& deformation of fluids \\
\hline Case Studies & Mechanics of Biomaterials; Composite Materials \\
\hline \multirow[t]{3}{*}{ Fluid Statics } & Force due to pressure \\
\hline & Forces on submerged surfaces \\
\hline & Buoyancy \\
\hline Case Study & St. Francis Dam \\
\hline \multirow[t]{4}{*}{ Fluid Dynamics: Governing Laws } & Description of fluid motion \\
\hline & Integral equations of motion \\
\hline & Differential equations of motion \\
\hline & Bernoulli equation \\
\hline Case Study & Three Gorges Dam \\
\hline \multirow[t]{2}{*}{ Fluid Dynamics: Applications } & Classification of fluid flows \\
\hline & Internal and external flows of interest \\
\hline Case Study & Flood Prevention Strategies in Netherlands, US \\
\hline Solid Dynamics & Governing equations \\
\hline
\end{tabular}

Student learning outcomes are listed in Table 2. 
Table 2. Student learning outcomes

\begin{tabular}{|c|c|}
\hline After completing this course, students will be able to: & $\begin{array}{l}\text { Relevant } \\
\text { ABET } \\
\text { criteria }\end{array}$ \\
\hline - $\quad$ Define the concepts of stress and strain & $3 a$ \\
\hline - Apply these concepts to wide range of engineering problems & $3 a, 3 e$ \\
\hline $\begin{array}{l}\text { - Possess sufficient physical intuition to identify relevance of continuum mechanics to the } \\
\text { design and analysis process }\end{array}$ & $3 c, 3 e$ \\
\hline $\begin{array}{l}\text { - Interpret and apply the governing equations for the motion and equilibrium of continuous } \\
\text { media }\end{array}$ & $3 e, 3 g$ \\
\hline - Describe the similarities and differences between solid and fluid responses to loading & $3 g$ \\
\hline $\begin{array}{l}\text { - Make both qualitative and quantitative predictions about complex systems, based on the } \\
\text { physical intuition developed in this course }\end{array}$ & $3 e, 3 k$ \\
\hline $\begin{array}{l}\text { - Identify, interpret, and distinguish the assumptions and approximations made in modeling } \\
\text { real problems; evaluate appropriateness of assumptions. }\end{array}$ & $3 e$ \\
\hline $\begin{array}{l}\text { - Identify tradeoffs made in ethical decision making; describe how professional ethics } \\
\text { evolved and are integrated into modern practice }\end{array}$ & $3 f, 3 k$ \\
\hline - Appreciate and articulate the interdependence of technology and society & $3 h, 3 j$ \\
\hline
\end{tabular}

Our pedagogical approach in this course (as in others taught by the authors ${ }^{9}$ ) is to communicate to students that engineering is a sociotechnical enterprise: that effective engineering practice will require both technical excellence and an appreciation of the realities of human culture, and its moral and political concerns. Over the last several decades engineering leaders have emphasized the role of the engineer in society through documents such as the National Academy of Engineering's Engineer of $2020^{10}$, the American Society of Civil Engineers' Body of Knowledge 11 , and ABET's Engineering Change report on the effects of the EC2000 accreditation criteria. ${ }^{12}$ Complementary historical and anthropological research, often produced by scholars of Science, Technology, and Society (STS), has repeatedly demonstrated the complex and multi-dimensional identity of technologies, and the mutual interdependence of the social and the technical. Examples of this work include the idea of technology as so-called "progress" "13 , as gendered ${ }^{14}$, and as culturally dependent not just in terms of individual values but even at the scale of national-cultural values ${ }^{15}$.

Our commitment to providing social context for technical content led us to integrate real-world case studies into the course. These demonstrated the relevance of various theories and analytical methods taught in the course, and also enabled class discussions to address ethical and sociopolitical issues that are integral, not peripheral, to the course. Two examples of topics included early on were the collapse of the Kansas City Hyatt walkways, and the construction of the Three Gorges Dam. In the case of the Hyatt walkways, we consider both the canonical ("Petroski"16) 
technical analysis of the failure and the societal consequences of the resulting investigation, including regulations and professional codes ("Pfatteicher"17). Students develop an appreciation of both the importance of their stress and deformation calculations and the ethical relevance of safety factors and accountability. Our integration of case studies also helped compensate for the potentially off-putting use of tensor notation and continuum mechanics in the new course by showing the direct applicability of the course material.

More recently, we have developed case studies that reflect the role of national "technological culture" in the diverse American and Dutch responses to the risk of flooding (which involves students performing calculations as well as reading and discussion relevant fiction, and builds to an in-class design experience); that consider the capabilities and the complexities of improved prosthetic designs for competitive athletes; and that describe the interdependence of the history of aviation, and airplane design evolution, with engineering beam theory. Our approach to the inclusion of professional ethics in technical coursework appreciates the reasoning of Lynch and Kline ${ }^{18-19}$, and focuses on "culturally embedded engineering practice." Several of the case studies also invoke literary and artistic perspectives on the central issue. We felt it critical to include case studies about construction, planning, and possibility, and not exclusively about structural failures and ethical lapses, in order to help students appreciate the engineering enabled by the course theories, and to develop a sense that ethical decision-making is relevant in all situations, not simply when trying to assign blame for a disaster.

\section{Transfer of Approach to New Institution}

The relocation of one of the authors to a new college presented an opportunity to test our theory that our approach was readily transferable. The institutions were similar in some ways: both undergraduate liberal arts colleges. However, at the new institution only half the students major in engineering, science, or math, as opposed to all of the students at the first college. Also, the new institution offers four ABET-accredited) BS programs in discipline-specific engineering (and one AB program in Engineering Studies), rather than a single unspecialized program in engineering.

In this context, the introduction to continuum mechanics fit best as a variation on the strength of materials course required of mechanical and civil engineering majors, and sometimes taken by other engineers as well. A course in statics is a prerequisite for strength of materials, and a course in fluid mechanics or transport is required of mechanical, civil, and chemical engineering majors. Thus, if the continuum approach is adopted in the strength of materials course, the curriculum provides plenty of opportunities to underscore its technical content, making it less "costly" to incorporate the case studies and continuum reasoning (if one is concerned with the conservation of technical content). Unlike the situation at the first college, each year multiple sections of strength of materials are offered by at least three distinct faculty members, only some of whom adopted the continuum approach. This created a situation where students from different sections could "compare notes" and find their own course dissatisfactory (feeling either that they were unfairly being asked to do more work and use higher math than other sections, or that they were unfairly being denied the additional understanding and demonstration opportunities offered to those in the continuum section); anecdotal evidence suggests that roughly equivalent numbers 
of students in both continuum and standard courses wished to be enrolled in the other version. (Their achievement of learning outcomes will be addressed in the Assessment section of this paper.)

The mathematical preparation of students is generally weaker at the second institution than at the first (where all incoming students, regardless of major, are required to have taken at least one year of calculus in high school). This required that we revise our continuum approach, to spend more time developing tensors and using visual methods like Mohr's circle to corroborate transformation equations. On the other hand, because a statics course is prerequisite at the second institution we could reduce our emphasis on free-body diagrams and static equilibrium analysis in this implementation of the continuum course.

\section{Assessment}

Through departmental assessment and evaluation processes, we have obtained both rubric- and survey-based data indicating that students are achieving the course's desired learning outcomes at both of the authors' institutions.

Rubrics have been developed to measure to what degree students develop particular skills, for example the ability to calculate the deflection of a beam's neutral axis or the principal stress state under given loading. These skills and rubrics follow directly from the learning objectives for the course, shown in Table 2. Sample rubrics are shown in Figure 2.

From our initial offerings, we were gratified to note that these skills were not diminished by the change in focus from dynamics and strength of materials to continuum mechanics. Student scores on learning outcomes such as their ability to prepare shear and bending moment diagrams, and their ability to analyze a member in torsion, have been consistently high, averaging 4.3 on a five-point scale (relative to a department goal or "expected level of attainment" of 4.0 or greater). We note that the students have achieved desired learning outcomes in skills we would have expected them to take from a course in statics and/or strength of materials, and from a course in fluid mechanics, and additional skills in continuum reasoning and writing that have been developed by the unique format of this course.

Our colleagues teaching advanced courses in structural mechanics, fluid mechanics, and continuum mechanics have indicated that alums of the introductory continuum mechanics course demonstrate a better understanding of the concepts of stress, strain, and kinematics; more readily understand finite element methods; and also perform better in applying beam theory and other structural models to a variety of static and dynamic applications. Because of its development of three-dimensional understandings of strain and stress, and its organic integration of tensor mathematics, this approach prepares students for more advanced elasticity formulations and computational approaches to both solid and fluid mechanics. 


\begin{tabular}{|l|l|}
\hline Skill \#1 Formulate and solve beam deflection problems (outcome 3e). \\
\hline Superior 5 & $\begin{array}{l}\text { Identifies, explains and solves the equilibrium equation(s) and boundary conditions to } \\
\text { determine the requisite deflection(s). Dimensions are consistent and correct. }\end{array}$ \\
\hline Good 4 & $\begin{array}{l}\text { Identifies (without explaining) and solves the equilibrium equation(s) and boundary } \\
\text { conditions to determine the requisite deflection(s). Solution is clear and well-annotated. }\end{array}$ \\
\hline OK 3 & $\begin{array}{l}\text { Identifies (without explaining) and solves the equilibrium equation(s) and boundary } \\
\text { conditions to determine the requisite deflection(s). Solution is unclear or poorly } \\
\text { organized. }\end{array}$ \\
\hline Marginal 2 & $\begin{array}{l}\text { Identifies (without explaining) and incorrectly (math, algebra, or dimensional error) } \\
\text { solves the equilibrium equation(s) and boundary conditions to determine the requisite } \\
\text { deflection(s). }\end{array}$ \\
\hline Inadequate 1 & $\begin{array}{l}\text { Incorrectly states equilibrium equation(s); incorrectly states boundary conditions; } \\
\text { completes calculations incorrectly. }\end{array}$ \\
\hline
\end{tabular}

\begin{tabular}{|l|l|}
\hline Skill \#2 Apply the principle of superposition to determine beam deflections (outcome 3a). \\
\hline Superior 5 & $\begin{array}{l}\text { Recognizes sub-problems that can be assembled to properly model the given problem } \\
\text { and correctly determines the proper component deflections. }\end{array}$ \\
\hline Good 4 & $\begin{array}{l}\text { Recognizes some/most of the sub-problems and determines appropriate (to his/her } \\
\text { recognition) deflections of sub-components. }\end{array}$ \\
\hline OK 3 & $\begin{array}{l}\text { Recognizes some/most of the sub-problems but makes at least one error in modeling } \\
\text { and/or calculation of deflection. }\end{array}$ \\
\hline Marginal 2 & Recognizes that superposition can be applied but is unable to perform decomposition. \\
\hline Inadequate 1 & Does not recognize role of superposition in analyzing beam deflections. \\
\hline
\end{tabular}

\begin{tabular}{|l|l|}
\hline Skill \#3 Write a clear, organized report of experimental work and analysis (outcome 3g). \\
\hline Superior 5 & $\begin{array}{l}\text { Prepares report with logical flow, and effective introduction and closing; report feels } \\
\text { complete. }\end{array}$ \\
\hline Good 4 & Makes some effort to make report flow effectively, not perfect. \\
\hline OK 3 & All sections are present, perhaps not in most effective order. \\
\hline Marginal 2 & Missing one section. No effort at transitional material. \\
\hline Inadequate 1 & $\begin{array}{l}\text { Missing multiple sections, weak transitions; poor or missing explanations of data, } \\
\text { equations, or schematics. }\end{array}$ \\
\hline
\end{tabular}

\begin{tabular}{|l|l|}
\hline Skill \#4 Explain and apply Bernoulli's equation, and justify its use (outcome 3e). \\
\hline Superior 5 & $\begin{array}{l}\text { Lists and justifies necessary assumptions, correctly calculates pressure drop or change in } \\
\text { fluid velocity along a known streamline. }\end{array}$ \\
\hline Good 4 & $\begin{array}{l}\text { Lists (without justifying) assumptions, correctly calculates pressure drop or change in } \\
\text { velocity along streamline. }\end{array}$ \\
\hline OK 3 & $\begin{array}{l}\text { Correctly calculates pressure drop or change in velocity without stating assumptions or } \\
\text { drawing streamline. }\end{array}$ \\
\hline Marginal 2 & $\begin{array}{l}\text { Recognizes that Bernoulli's equation should be applied, however, does not state } \\
\text { assumptions, and incorrectly completes calculation. }\end{array}$ \\
\hline Inadequate 1 & Does not recognize that Bernoulli's equation should be applied to problem. \\
\hline
\end{tabular}

Figure 2. Example rubrics for assessment of student learning outcomes on various assignments and exams. Note: with respect to Skill \#3 (relevant to outcome 3g), both institutions also use a multidimensional writing rubric to evaluate and provide feedback on student work. 
Our use of case studies in the course reading and in lectures and discussions has given students opportunities to consider the issues involved in real-world problems in essays and short-answer exam questions. Due to the inclusion of case studies in student reading, assignments, and exams, as well as in classroom discussions, we have also been able to evaluate learning outcomes such as oral and written communication skills and students' understanding of professional and ethical responsibility. As highlighted in Table 2, this permits the continuum course to address ABET outcomes $3 \mathrm{f}, 3 \mathrm{~g}, 3 \mathrm{~h}$ and $3 \mathrm{j}$ in addition to the more traditional $3 \mathrm{a}$ and $3 \mathrm{e}$, reflecting the multidimensionality of student learning in the course.

At the second institution, it is possible to directly compare student outcomes from the "continuum-flavored" strength of materials course with those from standard courses. The first author has herself taught a "standard-flavored" version of strength of materials, to facilitate such comparisons. As illustrated in Figure 3, the comparison casts the continuum approach in a favorable light: the average rubric ratings categorized by ABET outcome are higher for the continuum version of the course. Both versions of the course are more effective in developing outcome 3a (skill application) than outcome $3 \mathrm{e}$ (identification, formulating, and solving problems), which is consistent with the placement of the course early in the curriculum. In both courses, student performance on conceptual short-answer questions contributed to outcome $3 \mathrm{~g}$ (communication); in the continuum course, students have additional opportunities to write responses to case studies as well as the experiments and hands-on class work. Outcomes $3 \mathrm{f}, 3 \mathrm{~h}$, and $3 \mathrm{j}$ are not sufficiently addressed in a standard strength of materials course to be assessed.

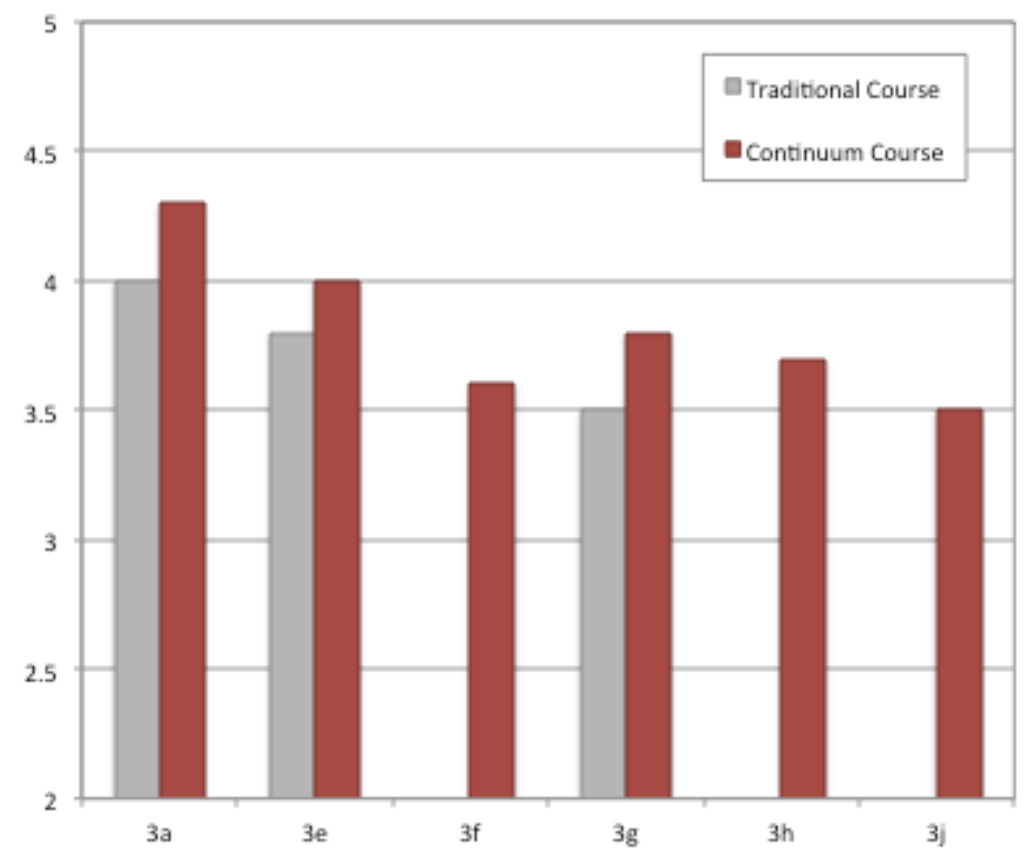

Figure 3 Comparison of student learning outcome achievement in continuum and standard courses. 
We also use student surveys to assess their own perceived learning outcome achievement. By focusing on outcomes related to the connections between solids and fluids, we hope to reinforce students' sense that these concepts and translational skills are important. Representative survey questions are shown in Figure 4.

\begin{tabular}{|c|c|c|c|c|c|c|}
\hline \multicolumn{7}{|c|}{ Rating Scale } \\
\hline None & \multicolumn{6}{|c|}{ I have no ability in this area at all } \\
\hline Minimal & \multicolumn{6}{|c|}{ I can name a few concepts under this area on my own and understand what they mean } \\
\hline Some & \multicolumn{6}{|c|}{ I can name, understand, and use some concepts to solve problems with some outside help } \\
\hline Modest & \multicolumn{6}{|c|}{ I can independently use the topics in this area to develop solutions to problems } \\
\hline Strong & \multicolumn{6}{|c|}{ I would feel comfortable expanding on what I know in this area to solve more advanced problems } \\
\hline & & None & Minimal & Some & Modest & Strong \\
\hline \multicolumn{7}{|c|}{ Identify assumptions relevant for fluid } \\
\hline \multicolumn{2}{|c|}{ mechanics problems } & $\square$ & $\square$ & $\square$ & $\square$ & $\square$ \\
\hline \multicolumn{7}{|c|}{ Extend understanding of stress and strain } \\
\hline \multicolumn{2}{|c|}{ in solids to fluids } & $\square$ & $\square$ & $\square$ & $\square$ & $\square$ \\
\hline \multicolumn{7}{|c|}{$\begin{array}{l}\text { Extend understanding of equilibrium, } \\
\text { constitutive laws and compatibility }\end{array}$} \\
\hline \multicolumn{2}{|c|}{ in solids to fluids } & $\square$ & $\square$ & $\square$ & $\square$ & $\square$ \\
\hline
\end{tabular}

Figure 4. Representative survey questions on connecting solid and fluid mechanics

Student comments from both institutions indicate that students are achieving the desired understanding of engineering mechanics as a field that includes solids, fluids, and many materials "in between" on the material behavior spectrum:

- 'I was glad to escape from classical physics and 'billiard ball' relations to understanding the internal forces in objects using the method of sections... What specifically interested me about beam theory was the application to construction, for example the World Trade Center discussion."

- "The idea of the tensor has expanded my view of the physical world and the way we describe it."

- 'the 'language' and 'art' of continuum mechanics."

We have been delighted by the creative ways our students have demonstrated their engagement with the course. These have included poems written, and videos produced, about the course material; dorm-room experiments on the material behavior of various unlikely materials that were well-documented and discussed in class; and in one case (Figure 5), an interpretive dance performed during the last class meeting. 


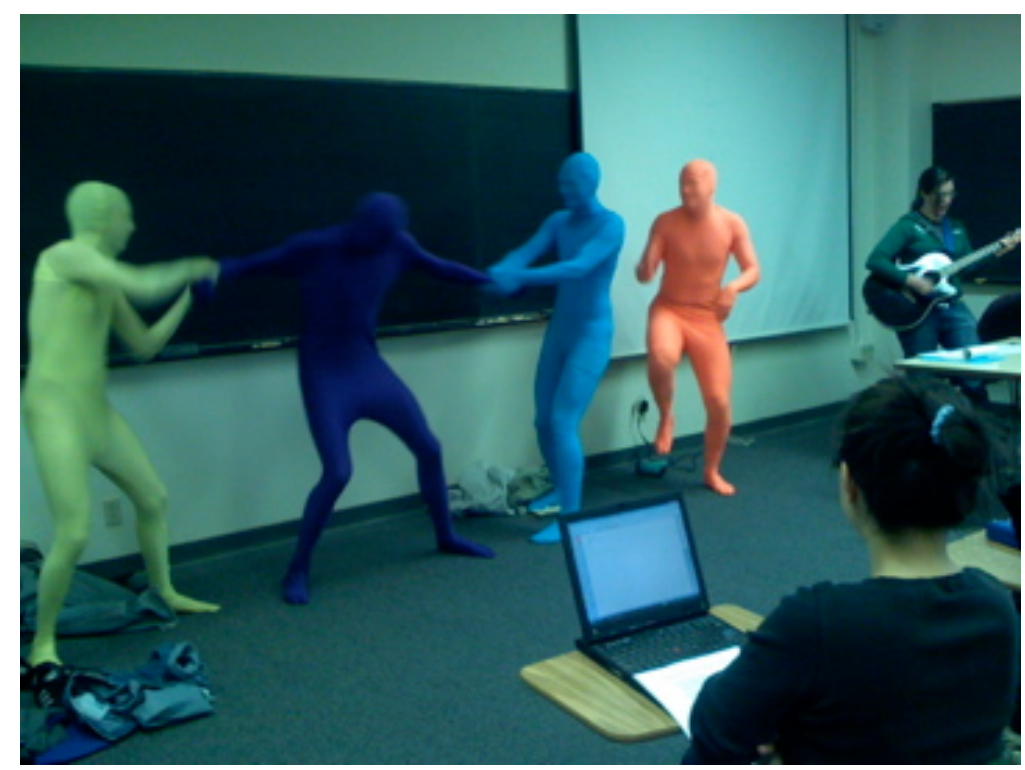

Figure 5. Interpretive dance demonstrating deformation of various materials, accompanied by student musicians playing original song written for the occasion.

\section{A Team Teaching Experiment}

One offering of the course was taught by a three-member teaching team. This yielded some additional applications that could be drawn into the course, and facilitated constructive dialogue. However, students came away with the impression that the course's segments were disparate and not organically connected. While additional faculty expertise enhanced the course content, the sense of course structure and unifying theme was lost. Having a single faculty member teach consistently throughout the semester is more effective in communicating the coherence and continuity of the course.

\section{Further Dissemination of Approach}

The approach has been adopted successfully elsewhere as a first introduction to (bio)mechanics for bioengineering majors, validating the authors' sense that the continuum approach would be an effective way to prepare students to analyze and design with the biomaterials that lie in the middle of the spectrum illustrated in Figure 1.

\section{Conclusions}

Using the language and mathematics of continuum mechanics has enabled us to introduce solid and fluid mechanics in one integrated sophomore-level course. By progressing gradually from single to higher dimensions, we have communicated the connections and distinctions between solids and fluid behavior, and introduced sophomores at two institutions to tensor mathematics. Students in the course learn an approach to modeling that is broadly transferrable, and develop a sophisticated, high-level appreciation of mechanics and materials. This approach is particularly valuable to their understanding of finite element models in both solid and fluid mechanics.

Although we have developed this approach in a specific institutional context, we have successfully transferred the approach to a second institution. The dual pressures to provide 
broader education and to reduce the number of credit hours - that is, to cover more material in less curricular time - are hardly unique to our colleges, and we have found that an early course in continuum mechanics is a reasonable and effective way to address these pressures. In addition to learning the desired material, students have responded very well to the continuum reasoning making connections between solids and fluids, and even to the tensor math involved.

Integrated case studies highlighting the relevance of course concepts in a wide range of applications, and addressing societal, political, and ethical issues, have helped students achieve both technical and professional learning outcomes. Reading and discussing case studies has demonstrated to students the utility of their technical knowledge, and has also widened their focus to include broader context. Quantitative and qualitative assessment indicates that students benefit from, and appreciate, the panoramic view provided by a sociotechnical, continuum approach to engineering mechanics.

\section{References}

1. A. Bright and C. L. Dym (2004) "General Engineering at Harvey Mudd: 1957-2003," Proceedings of the 2004 ASEE Annual Conference \& Exhibition.

2. C. L. Dym (1994) “Teaching Design to Freshmen: Style and Content,” Journal of Engineering Education, 83 (4), 303-310.

3. J. R. Phillips and A. Bright (1999) "The Harvey Mudd Engineering Clinic: Past, Present, and Future," Journal of Engineering Education, 88 (2), 189-194.

4. J.S. Rossmann and C.L. Dym (2004) "Continuum Mechanics as the First Mechanics Course," Proceedings of the 2004 ASEE Annual Conference \& Exhibition.

5. Y. C. Fung (1994) A First Course in Continuum Mechanics, 3rd Edition, Prentice Hall, Englewood Cliffs, NJ.

6. T. J. Chung (1996) Applied Continuum Mechanics, Cambridge University Press, New York.

7. G. T. Mase, R.E. Smelser, G. E. Mase (2009) Continuum Mechanics for Engineers, $3^{\text {rd }}$ Edition, CRC Press.

8. J.S. Rossmann, C.L. Dym, and L.C. Bassman (2015) Introduction to Engineering Mechanics: A Continuum Approach, $2^{\text {nd }}$ Edition, Taylor\& Francis/CRC Press.

9. B.R. Cohen, J.S. Rossmann, and K.L. Sanford Bernhardt (2014) "Introducing engineering as a socio-technical process," Proceedings of the 2014 ASEE Annual Conference \& Exhibition.

10. National Academy of Engineering (2004) The Engineer of 2020: Visions of Engineering in the New Century. Washington, D.C.: The National Academies Press.

11. American Society of Civil Engineers (2008) Civil Engineering Body of Knowledge for the $21^{\text {st }}$ Century: Preparing the Civil Engineer for the Future. $2^{\text {nd }}$ edition. Reston, VA: American Society of Civil Engineers. 
12. Lattuca, L.R., Terenzini, P.T., and Volkwein, J.F. (2006) Engineering Change: A Study of the Impact of EC2000. Baltimore, MD: ABET, Inc.

13. Smith, M. and Marx, L., eds. (1992) Does Technology Drive History? The Dilemma of Technological Determinism. Cambridge, MA: MIT Press.

14. Lerman, N., Oldenziel, R. and Mohun, A., eds. (2003) Gender and Technology: A Reader. Baltimore, MD: Johns Hopkins University Press.

15. Downey, G., Lucena, J. and Mitcham, C. (2007) "Engineering ethics and identity: Emerging initiatives in comparative perspective," Science and Engineering Ethics 13: 463-487.

16. H. Petroski (1992) To Engineer Is Human, Vintage.

17. S. Pfatteicher (2000) "'“The Hyatt Horror": Failure and Responsibility in American Engineering." J. Perform. Constr. Facil., 14(2), 62-66.

18. Lynch, W., and R. Kline. 2000. Engineering practice and engineering ethics. Science, Technology and Human Values 25: 195-225.

19. Kline, R. 2001. Using history and sociology to teach engineering ethics. IEEE Technology and Society 20(4): 13-20. 